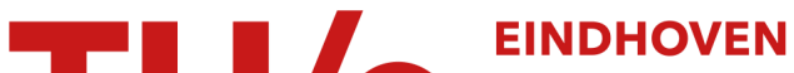 UNIVERSITY OF TECHNOLOGY
}

\section{Zinc electrode shape change I. In situ monitoring}

\section{Citation for published version (APA):}

Einerhand, R. E. F., Visscher, W., de Goeij, J. J. M., \& Barendrecht, E. (1991). Zinc electrode shape change I. In situ monitoring. Journal of the Electrochemical Society, 138(1), 1-7. https://doi.org/10.1149/1.2085538

DOI:

10.1149/1.2085538

Document status and date:

Published: 01/01/1991

\section{Document Version:}

Publisher's PDF, also known as Version of Record (includes final page, issue and volume numbers)

\section{Please check the document version of this publication:}

- A submitted manuscript is the version of the article upon submission and before peer-review. There can be important differences between the submitted version and the official published version of record. People interested in the research are advised to contact the author for the final version of the publication, or visit the $\mathrm{DOI}$ to the publisher's website.

- The final author version and the galley proof are versions of the publication after peer review.

- The final published version features the final layout of the paper including the volume, issue and page numbers.

Link to publication

\section{General rights}

Copyright and moral rights for the publications made accessible in the public portal are retained by the authors and/or other copyright owners and it is a condition of accessing publications that users recognise and abide by the legal requirements associated with these rights.

- Users may download and print one copy of any publication from the public portal for the purpose of private study or research.

- You may not further distribute the material or use it for any profit-making activity or commercial gain

- You may freely distribute the URL identifying the publication in the public portal.

If the publication is distributed under the terms of Article 25fa of the Dutch Copyright Act, indicated by the "Taverne" license above, please follow below link for the End User Agreement:

www.tue.nl/taverne

Take down policy

If you believe that this document breaches copyright please contact us at:

openaccess@tue.nl

providing details and we will investigate your claim. 


\title{
ELECTROCHEMICAL SCIENCE AND TECHNOLOGY
}

\section{Zinc Electrode Shape Change

\author{
I. In Situ Monitoring
}

R. E. F. Einerhand' and W. Visscher

Laboratory for Electrochemistry, Eindhoven University of Technology, 5600 MB Eindhoven, The Netherlands

\author{
J. J. M. de Goeij
}

Laboratory for Instrumental Analysis, Eindhoven University of Technology, $5600 \mathrm{MB}$ Eindhoven, The Netherlands and Interfaculty Reactor Institute, Delft University of Technology, $2629 \mathrm{JB}$ Delft, The Netherlands

\section{E. Barendrecht}

Laboratory for Electrochemistry, Eindhoven University of Technology, $5600 \mathrm{MB}$ Eindhoven, The Netherlands

\section{ABSTRACT}

Zinc electrode shape change, the redistribution of zinc material over the electrode during repeated cycling, has been identified as one of the main life-limiting factors for alkaline nickel oxide/zinc secondary batteries. To investigate this phenomenon in situ, a radiotracer, ${ }^{65} \mathrm{Zn}$, is incorporated in the battery and its movement monitored during repeated cycling of the battery. The changes in the distribution of ${ }^{65} \mathrm{Zn}$ over the electrode during battery operation are attributed to the displacement of radioactive zincate ions via the battery electrolyte. It is shown that the spatial distribution of ${ }^{65} \mathrm{Zn}$ offers a reliable indication for the zinc material distribution over the electrode, provided an electrode with uniformly specific radioactivity is used in the measurements. Radiotracer experiments using zinc electrodes containing 2 weight percent $\mathrm{HgO}$ as an additive and uniformly labeled with ${ }^{203} \mathrm{Hg}$, have revealed that during battery cycling no substantial net transport of mercury species occurs. It is concluded that it is highly unlikely that the mercury additive detaches from or moves over the zinc electrode surface during the cycling process. Also, these experiments show that zinc material transport as a result of detachment of electrode mass did not occur.

The nickel oxide/zinc secondary battery is still the most promising candidate for electric vehicle propulsion purposes. It has a relatively high operating voltage and a high energy and power density. Furthermore, it can be used within a wide temperature range, is relatively cheap, and does not constitute an environmental threat as many other battery systems do.

The main disadvantage of this battery is its limited cycle life, due to the degradation of the zinc electrode. Shape change, dendrite shorting, and to lesser extent passivation and densification of the zinc electrode have been identified as the principal causes for the poor cycle life of the zinc electrode. The problem of dendrite formation has been largely overcome by improvements in separators and by additives to the electrode and electrolyte which mitigate dendritic growth of zinc.

Shape change refers to the reduction of the electrochemically active surface area of the zinc electrode during repeated cycling of the battery, as a result of the redistribution of zinc material over the electrode. Studies about shape change have revealed that cell and electrode geometry, depth of discharge, type of separator, and additives to the zinc electrode and battery electrolyte are the most important factors which influence the extent and rate of shape change. As yet, however, a solution to shape change is not envisaged.

The solution to shape change must come from a thorough understanding of the fundamental phenomena involved in the redistribution of zinc material over the electrode. Therefore, the aim of this study is to elucidate the process and mechanism of shape change, leading to a model, which can account for the observed phenomena

${ }^{1}$ Present address: Philips Research Laboratories, 5600 JA Eindhoven, The Netherlands. and, hopefully, can indicate how shape change can be prevented. These aspects of our study will be treated in part II (Process and Mechanism) of this paper. In this part (part I), the monitoring of shape change during repeated cycling of the nickel oxide/zinc secondary battery is investigated. This is essential to gain insight in the rate and direction of the zinc material transport in the battery.

The study of zinc electrode shape change has been performed by ex situ and in situ techniques (1-8). In the elaborate ex situ and, hence, "post-mortem" analysis of the shape change phenomenon, the zinc and zinc oxide distribution over the zinc electrode is determined gravimetrically and colorimetrically (1-3). The in situ techniques are based on the determination of the superficial current density distribution over the zinc electrode. A decrease of the local current density implies a loss of active material on that part of the electrode and, inversely, an increase of current density implies an accumulation of active material. However, this approach does not account for changes in current density distribution due to other causes, like alteration of electrolyte conductance or passivation and densification of the electrode.

Furthermore, the current density distribution is not measured directly, but is deduced from the determination of the potential distribution over the zinc electrode $(4,5)$ or from the current density distribution over a sectioned counterelectrode (6-8). Thereby, it is assumed that the measured parameter and the current density distribution are continually related in a straightforward way, which is certainly untrue.

An even more serious drawback of this technique, in fact of all techniques applied up till now, is that information is obtained on the overall process rather than on the movement of zinc species over the electrode during the cycling 
process. Therefore, it is investigated whether zinc electrode shape change can be monitored in situ using a novel approach, i.e., the incorporation of a radiotracer, ${ }^{65} \mathrm{Zn}$ (halflife 244 days), in the battery and following its movement when cycling the nickel oxide/zinc battery (9). The location of labeled material in the battery can be determined by measurement of the spatial distribution of the radioactivity in the battery. Since the chemical and physical properties of the radiotracer are, apart from its radioactivity, identical to nonradioactive zinc, the movement of the radiotracer indicates the movement of zinc material over the electrode. Also, since in this study (part I) homogeneously labeled electrodes, i.e., electrodes with uniform specific radioactivity (radioactivity per unit weight of labeled material) are used, the measured radioactivity distribution should indicate the distribution of zinc over the electrode. However, with the radiotracer technique it is virtually impossible to distinguish between zinc species in the electrolyte and on the electrode or between metallic zinc and oxidized zinc species. Thus zinc material refers to all species which entrain zinc, whether on the electrode [e.g., $\mathrm{Zn}$, $\mathrm{ZnO}, \mathrm{Zn}(\mathrm{OH})_{2}, \mathrm{~K}_{2} \mathrm{Zn}(\mathrm{OH})_{4}$ or in solution [e.g., $\mathrm{Zn}(\mathrm{OH})_{3}{ }^{-}$, $\mathrm{Zn}(\mathrm{OH})_{4}{ }^{2-}$, polymeric zincate ions].

Recently, Hietbrink and Hill investigated the movement of the electrolyte in the battery and the redistribution of zinc during repeated cycling of a nickel oxide/zinc accumulator, using ${ }^{137} \mathrm{Cs}$ and ${ }^{65} \mathrm{Zn}$, respectively, as radiotracers (10). They concluded that zinc material is transported via the battery electrolyte predominantly towards the center of the electrode. However, surprisingly, at the end of the cycling experiment (ending with a discharge half-cycle) they observed that no radioactive zinc material was present in the battery electrolyte. Also, they could not relate the movement of the radiotracers to the zinc material transport in the battery and to the observed shape change pattern on the zinc electrode, because they did not perform an analysis of the zinc electrode.

One of the most commonly used additives to the zinc battery plate is mercury or mercuric oxide. It is wellknown that shape change is accelerated when mercuric oxide is added to the zinc battery plate (11). The origin of this deleterious effect is scarcely understood in spite of the fair amount of studies (11-13). The role of the mercury additive with respect to shape change can also be studied with the radiotracer technique. ${ }^{203} \mathrm{Hg}$ (half-life 46.8 days) is incorporated in the zinc electrode and the spatial distribution of the radiotracer over the electrode is monitored during repeated cycling of the secondary battery.

\section{Experimental}

Zinc electrode preparation and cell assembly.-Polytetrafluoroethylene (PTFE)-bonded zinc oxide (12) is used for the preparation of the zinc electrodes. This PTFEbonded zinc oxide is pressed onto a silver-plated nickel screen $(35 \times 39 \times 0.3 \mathrm{~mm})$ to obtain a zinc electrode with a thickness of about $0.7 \mathrm{~mm}$ and a theoretical capacity of $1.3 \mathrm{Ah}$ (5). The electrode is wrapped in a separator, Rai P-2291 40/20, a weak cationic membrane, and sandwiched between two sintered nickel oxide electrodes $(35 \times 39 \times 0.8 \mathrm{~mm}, 0.4 \mathrm{Ah}$ in capacity each, Varta, Germany). The battery is assembled in the discharged state.

The experiments are carried out, using polyacrylate cells (internal dimensions, $h \times l \times w, 100 \times 37 \times 4 \mathrm{~mm}$ ) in which the electrodes are placed parallel to the earth gravitational field. The batteries are operated in the flooded and vented mode.

The battery electrolyte is prepared from doubly distilled water, AnalaR grade potassium hydroxide and zinc oxide with initial concentrations of 10 and $1 M$, respectively. Since zinc oxide is quantitatively converted to zincate according to reaction [1]

$$
\mathrm{ZnO}+\mathrm{H}_{2} \mathrm{O}+2 \mathrm{OH}^{-} \rightarrow \mathrm{Zn}(\mathrm{OH})_{4}{ }^{2-}
$$

the hydroxyl ion concentration decreases from 10 to approximately $8 M$.

The air in the electrolyte and electrodes is removed by placing the assembled cell in a vacuum chamber for at least $30 \mathrm{~min}$.
The ${ }^{65} \mathrm{Zn}$ and ${ }^{203} \mathrm{Hg}$ radiotracers are prepared by neutron irradiation of (PTFE-bonded) zinc oxide and mercuric oxide, respectively. The irradiations are performed at the Interfaculty Reactor Institute at Delft. The irradiated samples are stored for about four weeks to allow induced short-lived activity to decay, e.g., ${ }^{69 \mathrm{~m}} \mathrm{Zn}(13.9 \mathrm{~h}),{ }^{197} \mathrm{Hg}(64 \mathrm{~h})$, and ${ }^{197 m} \mathrm{Hg}(24 \mathrm{~h})$. After this decay, the radionuclide purity of the radiotracer is checked by $\mathrm{Ge}(\mathrm{Li})$ gamma spectrometry. The specific radioactivity of the radioactive samples is in the order of $50 \mathrm{GBq} \cdot \mathrm{kg}^{-1}$ for ${ }^{65} \mathrm{Zn}$ and $300 \mathrm{GBq} \cdot \mathrm{kg}^{-1}$ for ${ }^{203} \mathrm{Hg}$. Three series of experiments are performed:

1. ${ }^{65}$ Zinc-labeled electrode: Radioactive PTFE-bonded zinc oxide is thoroughly mixed with nonradioactive PTFE-bonded zinc oxide. This mixture is used to prepare an electrode with uniform specific radioactivity. The electrolyte is prepared from nonradioactive $\mathrm{ZnO}$.

2. ${ }^{65}$ Zinc-labeled electrolyte: The battery is assembled with initially nonradioactive electrodes. The battery electrolyte is prepared from radioactive zinc oxide.

3. ${ }^{203} \mathrm{Hg}$-labeled electrode: Radioactive mercuric oxide is thoroughly mixed with PTFE-bonded zinc oxide and this mixture is used to prepare a uniformly labeled electrode containing 2 weight percent (w/o) HgO.

Battery cycling tests.--The nickel oxide/zinc batteries are cycled galvanostatically with a current of $0.2 \mathrm{~A}$ (73 $A \cdot \mathrm{m}^{-2}$ ). The cycling experiment starts with a charge halfcycle. Cell voltage and zinc electrode potential (vs. a $\mathrm{Hg} / \mathrm{HgO}$ reference electrode), during charge and discharge, are recorded for all batteries. A device is developed for automatically cycling of the batteries. The charge processes is ended if the preset time of $2.5 \mathrm{~h}$ or if the cell cutoff voltage of $2.1 \mathrm{~V}$ is exceeded. The discharge process is continued until the cell voltage drops below $1.2 \mathrm{~V}$. At the end of a half cycle (charge or discharge), a rest period of $0.5 \mathrm{~h}$ is introduced.

The detection of radioactivity. $-{ }^{65} \mathrm{Zn}$ disintegrates with a half-life of 244 days via electron capture and emission of a gamma ray and/or emission of a positron to stable ${ }^{65} \mathrm{Cu}$. A simplified decay scheme is presented in Fig. 1A. The gamma ray, used for detection of ${ }^{65} \mathrm{Zn}$, has a energy of 1.116 $\mathrm{MeV}$ and an emission probability of $50.7 \%$. The annihilation of the positron produces two gamma rays with an energy of $0.511 \mathrm{MeV}$ each.

Figure $1 \mathrm{~B}$ shows the decay scheme of ${ }^{203} \mathrm{Hg}$, which disintegrates with a half-life of 46.8 days to stable ${ }^{203} \mathrm{Tl}$, via emission of $\beta^{-}$particles and a gamma ray with an energy of $0.279 \mathrm{MeV}$ and an emission probability of $81.5 \%$.

The radiotracer measurements are performed during the rest period of the battery cycling regimen. The experimental setup for the gamma ray measurement is given in Fig. 2. The cell is positioned stepwise by a set of blocks, thus enabling the measurement of the radioactivity at nine regions on the zinc electrode. These nine regions on the zinc electrode are depicted in Fig. 3 for two types of collimators, a "conical" and a "rectangular" one.

The conical collimator consists of a brick of lead $(200 \times 100 \times 100 \mathrm{~mm})$ in which a conical hole is made. The radius of the circular cross section at the cell side is $5.5 \mathrm{~mm}$
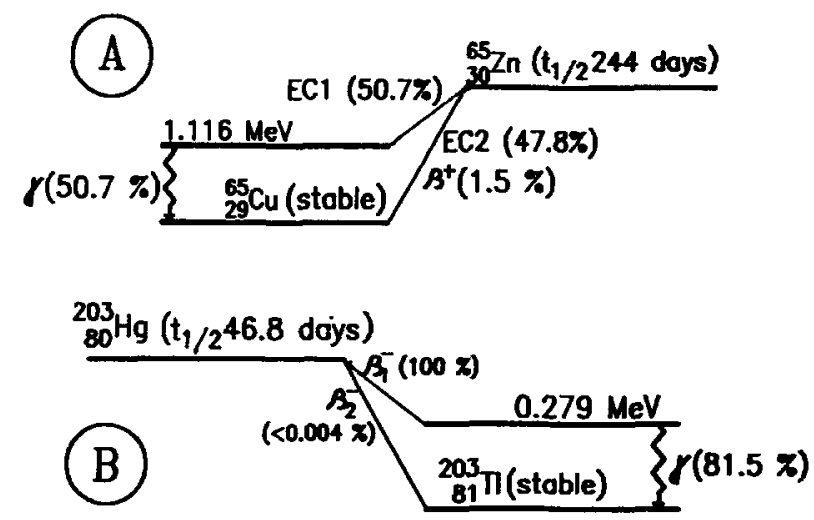

Fig. 1. Simplified decay scheme of ${ }^{65} \mathrm{Zn}(\mathrm{A})$ and ${ }^{203} \mathrm{Hg}(B)$ 


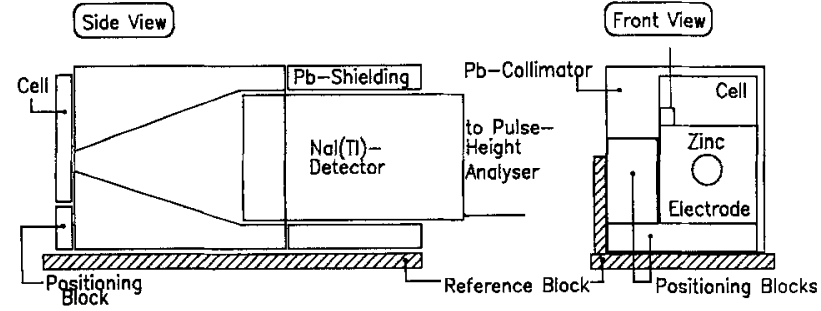

Fig. 2. Experimental setup for the radiotracer measurements

and at the detector side $40 \mathrm{~mm}$. The geometrical efficiency, i.e., the ratio of the surface area of the detector which can detect radiation directly, and the surface area of an imaginary sphere with a radius equal to the distance of the radiation source from the detector, for the conical collimator is about $1 \%$. Due to this relatively "high" efficiency low activities can be measured over acceptable time intervals. With the positioning of the cell in front of this collimator the radioactivity at about $95 \%$ of the zinc electrode area can be determined.

The rectangular collimator is manufactured from a brick of lead $(150 \times 100 \times 100 \mathrm{~mm})$ in which a rectangular hole $(13.00 \times 11.67 \mathrm{~mm})$ is made. The dimensions of this hole at the cell side and at the detector side are identical. With this collimator the radioactivity over the total surface of the zinc electrode can be detected, but the specific radioactivity of labeled material must be higher than with the conical collimator, since its geometrical efficiency is only about $0.05 \%$.

The $1.116 \mathrm{MeV}$ gamma ray of ${ }^{65} \mathrm{Zn}$ and the $0.279 \mathrm{MeV}$ gamma ray of ${ }^{203} \mathrm{Hg}$ are detected with a cylindrical NaI(T1) scintillation crystal with a radius of $38.1 \mathrm{~mm}$ and a length of $76.2 \mathrm{~mm}$. For ${ }^{65} \mathrm{Zn}$ the pulse-height analyzer is set to measure photons with an energy between 1.05 and 1.25 $\mathrm{MeV}$, for ${ }^{203} \mathrm{Hg}$ the setting is between 0.255 and $0.305 \mathrm{MeV}$. These settings reduce interference in the measurements of lower energy (Compton or scattered) photons. All measurements are performed with a preselected time interval. Its magnitude depends on the observed counting rate, i.e., the number of measured pulses in the photopeak per second, to obtain a statistical error lower than $5 \%$. The observed counting rate at a region on the electrode, $n_{\mathrm{r}}$, is corrected for the background counting rate due to natural radiation, $n_{\mathrm{b}}$, and for the decay of the radionuclide. Thus, the background and decay corrected counting rate, $n_{\mathrm{r}, \mathrm{c}}$, is calculated from the formula

$$
n_{\mathrm{r}, \mathrm{c}}=\left(n_{\mathrm{r}}-n_{\mathrm{b}}\right) \cdot \exp \left(\ln 2 \cdot \Delta t / t_{1 / 2}\right)
$$

In this equation, $\Delta t$ is the time elapsed since the start of the cycling experiment and $t_{1 / 2}$ the half-life of the radionuclide. The exponential term in Eq. [2] corrects the radioactivity data for the decay of the radionuclide since the start of the cycling experiment. Therefore, the radioactivity data of a certain region on the electrode can be interpreted
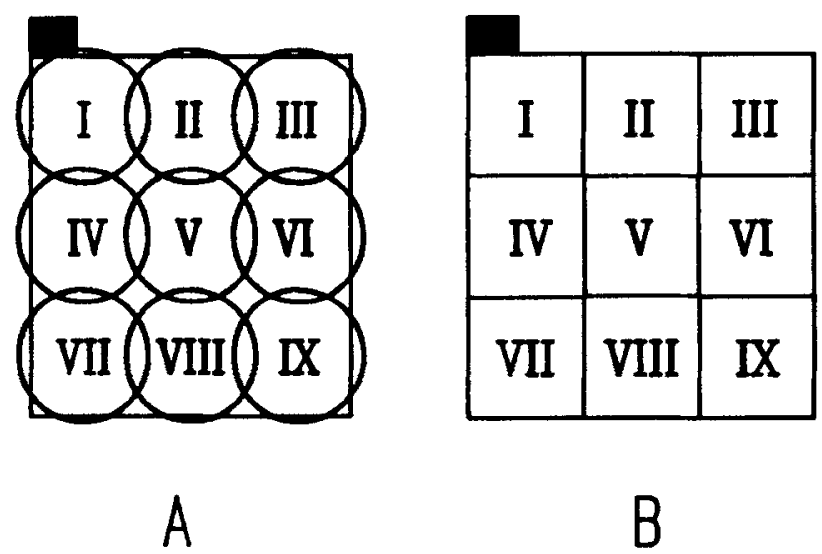

Fig. 3. Subdivision of the surface of the zinc electrode for measurements with the conical (A) and rectongular collimator (B). directly. From the background and decay corrected counting rate the radioactivity at a certain region on the electrode, $A_{\mathrm{r}}$ (in $\mathrm{Bq}$ ), is calculated from the formula

$$
A_{\mathrm{r}}=n_{\mathrm{r}, e} \cdot \lambda
$$

where $\lambda$ is the conversion factor, including the efficiency of the experimental setup and the emission probability of the radionuclide. The efficiency of the experimental setup is determined from the measurement of the counting rate of $a^{65} \mathrm{Zn}$ or ${ }^{203} \mathrm{Hg}$ calibration source, of which the activity is accurately known at the time of the measurement.

The gamma rays, in particular the ${ }^{65} \mathrm{Zn}$ gamma rays, originating from regions surrounding the region being measured cannot be shielded completely by the collimators. In a separate study this matter is investigated (14): it is shown that application of corrections of the radioactivity data for radiation from surrounding regions yielded plots which showed trends similar to the plots based on the uncorrected data. At the start of the experiment the differences in radioactivity at the nine regions tend to decrease when the corrections are applied. However, since the correction procedure itself introduces additional errors, the gain in accuracy is only marginal. Therefore, it was decided to omit the correction step, the more so, as the changes in the curves are more important than the absolute values.

Ex situ electrode analysis.-At the end of the cycling tests the batteries are disassembled and photographs are taken from the zinc electrodes. Then, the radioactivity distribution over the zinc and nickel electrodes is determined separately. The electrolyte radioactivity is also examined. The electrode mass is scraped from the nine fictitious regions $(13.00 \times 11.67 \mathrm{~mm})$ on the zinc electrode. The nine samples are weighed and their radioactivity, specific radioactivity, and zinc and PTFE content established.

\section{Results and Discussion}

${ }^{65} \mathrm{Zn}$ distribution at open-circuit potential.-To establish the rate of exchange of radioactive $\mathrm{ZnO}$ on the electrode with nonradioactive zincate ions in the electrolyte, a battery is assembled with a freshly prepared electrode of which a small part is made radioactive: a spot electrode [the preparation of this type of electrode is described in part II (15)]. This battery is not cycled, but is kept at opencircuit potential over more than four months. The radioactivity of the radioactive spot remains virtually constant during this period, and the radioactivity of the electrolyte at the end of the test is less than $2 \%$ of the radioactivity at the spot. This indicates that though the battery electrolyte is not $\mathrm{ZnO}$ saturated, the chemical dissolution rate of $\mathrm{ZnO}$ and the exchange with zincate ions in solution is small, as was found also by Dirkse et al. (16). Hence, during repeated cycling any change in radioactivity over the electrode must be the result of the charge and discharge processes in the battery.

Cycling experiment with ${ }^{65} \mathrm{Zn}$ in the electrode.-In situ monitoring of the shape change pattern.-An electrode with uniform specific radioactivity is continuously cycled in a vertical cell filled with nonradioactive electrolyte. The change of the relative capacity during the cycling process is given in Fig. 4. The relative capacity is defined here as the ratio of the charge output and the predetermined charge input (i.e., $0.5 \mathrm{Ah}$ ). It is observed that the battery can accept the predetermined amount of charge for about nine cycles. The current efficiency is better than $95 \%$, except for the first cycles. The relative capacity drops to about $40 \%$ in the next 20 cycles and remains at this level for another 20 cycles. At the end of the cycling test, after 52 cycles, the electrode is taken from the cell and shape change is observed.

During the cycling experiment the distribution of the radiotracer over the electrode is monitored with the conical collimator. The change of the radioactivity in each of the nine regions on the electrode is depicted in Fig. 5 . The figure shows that the movement of the radiotracer occurs from the start of the experiment. During cycling, the radioactivity at the three top regions decreases, whereas at the bottom regions it increases. The rate of change in the 


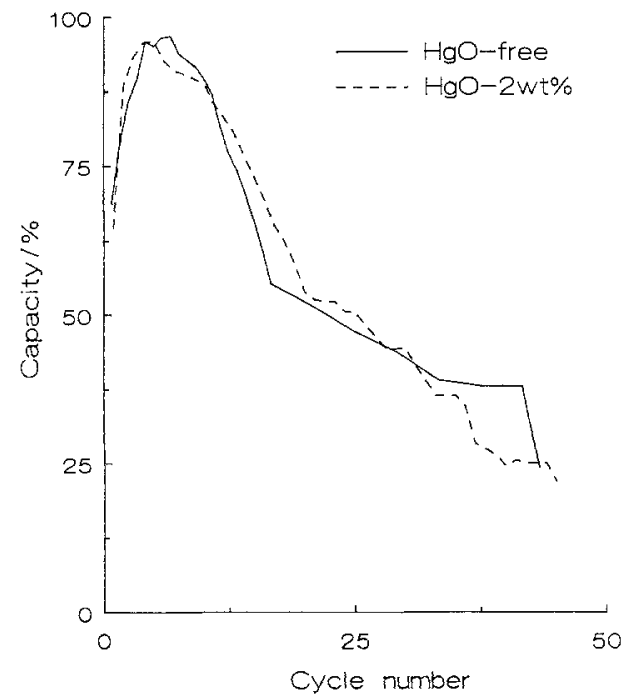

Fig. 4. Relative battery capacity for the bottery with the zinc electrode with uniform specific radioactivity, as a function of cycle number. Solid curve: battery with a $\mathrm{HgO}$-free zinc electrode. Dashed curve: battery with a 2 w/o $\mathrm{HgO}$ containing zinc electrode.

measured radioactivity over the electrode becomes smaller as battery cycling proceeds.

The radioactivity at a certain region on the electrode is related to the amount of labeled material at that region. Since, the specific radioactivity over the electrode is uniform from the very beginning, it will remain constant in time (the chemical and physical properties of the radiotracer are, apart from its radioactivity, identical to nonradioactive zinc). Indeed, at the end of the cycling experiment, ex situ analysis of the zinc electrode shows that the specific radioactivity over the electrode is uniform. So, the amount of labeled material at a particular region on the electrode presents an indication for the total amount of zinc material at that region.

At the start of the cycling experiment the measured radioactivity at the individual regions differ. This can be attributed to inaccuracy in the measurement of the radioactivity, and possibly, to a minor extent to small differences in zinc electrode thickness and to local inhomogeneities in specific radioactivity. Nevertheless, changes in the spatial distribution of the measured radioactivity must be due to changes in the zinc material distribution, as was concluded from a detailed analysis of the accuracy of our radiotracer experiments (14).

Therefore, the radioactivity distribution presented in Fig. 5 shows that during cycling significant changes of the zinc material distribution occur. The top of the electrode loses zinc material which agglomerates at the bottom of the electrode. Thus, the redistribution of zinc material over the electrode, i.e., zinc electrode shape change, can be monitored in situ.

$E x$ situ determination of the shape change pattern.-The radiotracer technique can also be applied for ex situ analysis of the zinc material distribution over the electrode. After 52 charge-discharge cycles the electrode was taken from the cell and the radioactivity over the electrode was measured. In Fig. 6 the relative radioactivity distribution is presented, which may be compared with the relative electrode mass distribution and the photograph of the electrode, given in Fig. 7 and 8 , respectively. The zine material distributions derived from these three figures are in general agreement.

The photograph shows that shape change has occurred. It offers a general impression of how zinc material is distributed over the zinc electrode surface. The electrode mass distribution, given in Fig. 7, offers a less qualitative picture of the zinc material distribution, but the relation between zinc material and electrode mass distribution is only semi-quantitative, because PTFE and probably water and $\mathrm{KOH}$ are embedded in the electrode mass. In fact, it is found that for all electrodes the amount of PTFE per region is nearly equal over the electrode and close to the theoretically expected value. Apart from the fact that PTFE is not transported over the electrode, this result confirms that the electrode mass distribution is only a very rough estimate for the zinc material distribution. The radioactivity distribution is quantitatively related to the zinc material distribution provided the specific radioactivity over the electrode is uniform. Hence, the radiotracer technique also provides a nondestructive and nonelaborate method for the ex situ determination of the shape change pattern on the zinc electrode.

At the end of the cycling process the radioactivity distribution $\left({ }^{65} \mathrm{Zn}\right)$ over the nickel electrodes was also determined. Roughly, a similar distribution is found as for the zinc electrode except that the amount of radioactivity is much smaller.

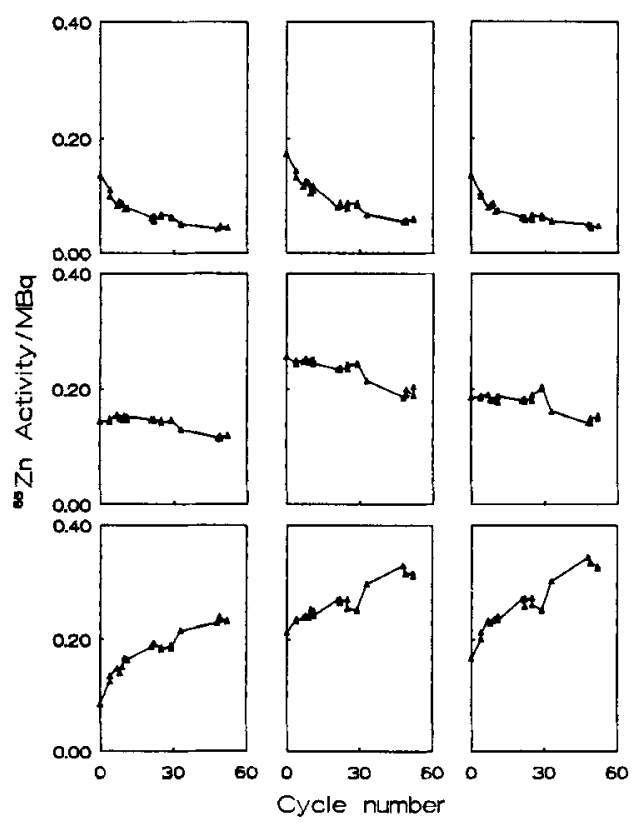

Fig. 5. The change in radioactivity $\left({ }^{65} \mathrm{Zn}\right)$ at the nine regions on the electrode (cf. Fig. 3) with uniform specific radioactivity during cycling. Meosurements are performed with the conical collimator.

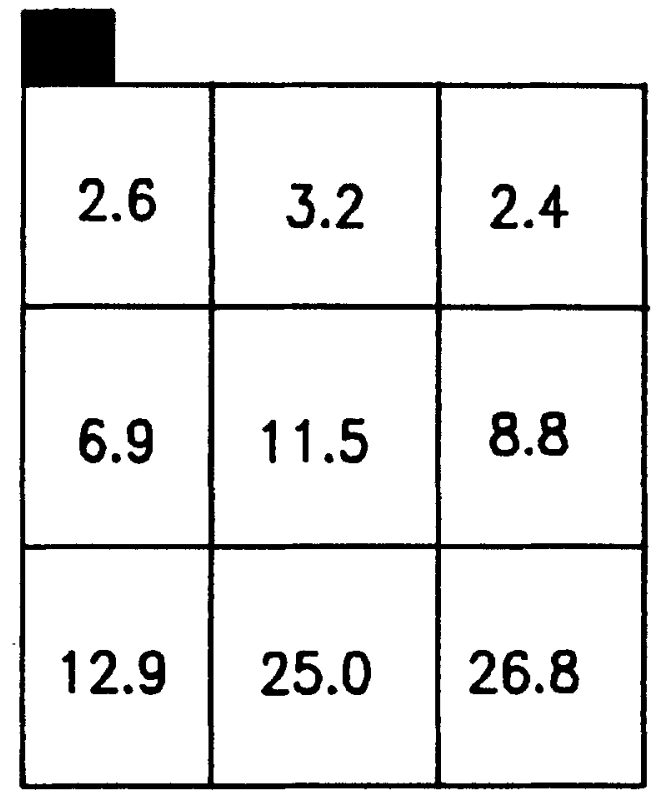

Fig. 6. Relative radioactivity $\left({ }^{65} \mathrm{Zn}\right)$ distribution at the nine regions on the electrode (cf. Fig. 3) with uniform specific radioactivity, measured after $\mathbf{5 2}$ cycles. The radioactivity is measured with the conical collimator. 


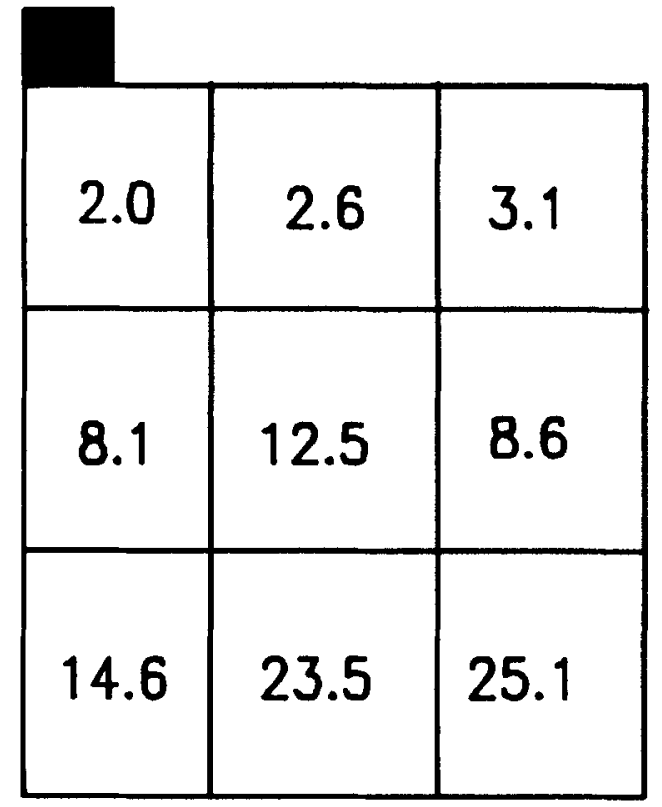

Fig. 7. Relative electrode mass distribution at the nine regions on the zinc electrode (cf. Fig. 3) with uniform specific radioactivity ofter 52 cycles.

Typically, about 5 to $10 \%$ of the total radioactivity is found on the nickel electrodes, about $2-4 \%$ in the battery electrolyte and the balance on the zinc electrode. This indicates that during one cycle approximately $0.1 \%$ of the total amount of ${ }^{65} \mathrm{Zn}$ is transported from the zinc electrode towards the nickel electrode compartment, assuming a negligible transport in the opposite direction.

Cycling experiment with ${ }^{65} \mathrm{Zn}$ in the electrolyte.-For a uniformly labeled electrode the contribution of radiation from radioactive zincate ions in solution to the measured radioactivity over the electrode is expected to be negligible, since the amount of zinc material is much larger in the electrode than in the electrolyte. However, the radioactivity distribution as observed in Fig. 5 changes drastically within a few cycles, which is attributed to the movement of zincate ions in solution. Though during charge the zincate concentration will be small, it may rise appreciably during discharge.

The influence of radioactive zincate ions in solution on the measured radioactivity distribution is examined by performing a cycling experiment with a battery assembled with an initially nonradioactive zinc electrode and a radioactive $\left({ }^{65} \mathrm{Zn}\right)$ electrolyte. After 52 cycles the cycling experiment is discontinued and zinc electrode shape change is observed.

The radioactivity distribution during the cycling test is determined using the conical collimator and is given in Fig. 9. Similar to the results depicted in Fig. 5 the top regions lose and the bottom regions gain radioactive material. However, in contrast with the results of the experiment with a uniformly labeled electrode, during the first five cycles the radioactivity at all regions on the electrode increases, most noticeably at the three top regions. Since the increase in radioactivity is observed at all regions, the radioactivity increase at the three top regions cannot be attributed to the movement of radioactive zincate ions from the bottom or middle regions towards the top of the electrode. It must be caused by the deposition of radioactive zincate ions, which are supplied by the electrolyte just over the top of the electrodes: the electrolyte reservoir, which is not seen by the detector, and hence, not taken into account in the radioactivity measurement.

During these first cycles the specific radioactivity over the zinc electrode and in the battery electrolyte will change markedly, due to mixing of nonradioactive zinc material on the electrode with radioactive zinc material in the electrolyte. After these first cycles, the changes become gradually less pronounced. However, since the deposition of zincate ions differs for different regions on the electrode and since at the top regions a large electrolyte reservoir is present, from which radioactive zincate ions can be supported, the specific radioactivity over the electrode will not be constant. Also, the specific radioactivity will be affected by the extent of penetration of radioactive zincate ions into the porous electrode, by the thickness of the electrode and by the redissolution of zinc. Thus, though the trend of the plots in Fig. 5 and 9 are similar, at least after the first few cycles, only an estimate of the zinc material distribution can be obtained from the experiment with the battery with initially only radioactive zinc material in the electrolyte.

The increase of radioactivity at the top positions at the start of the cycling experiment indicates that the existence and position of an electrolyte reservoir is of crucial importance for zinc electrode shape change. It also shows that zincate ions are transported over the electrode via the battery electrolyte.

Hietbrink and Hill (10) pointed out that electrolyte movement in the battery plays an important role with respect to shape change. The results of their experiments with ${ }^{137} \mathrm{Cs}$ added to the battery electrolyte, which was used as a substitute for radioactive potassium, showed that elec-
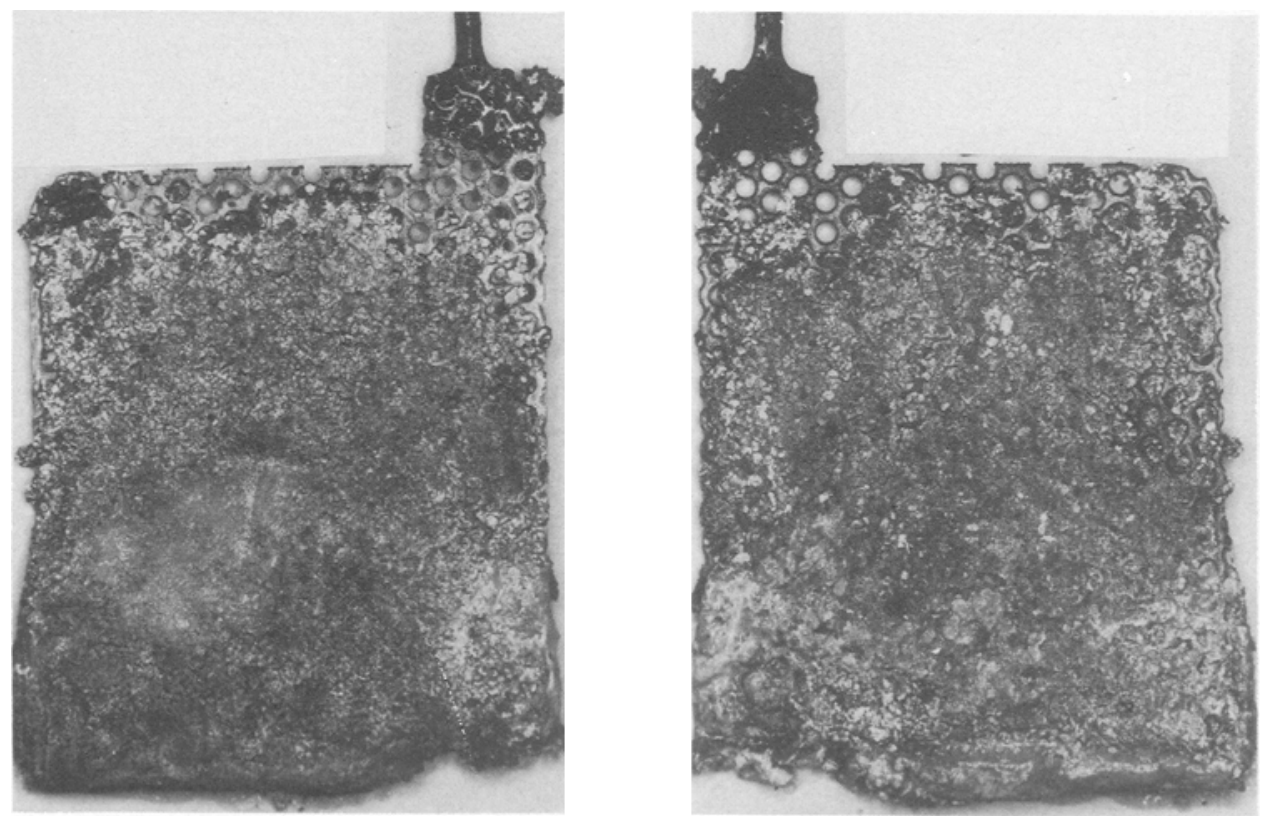

Fig. 8. Photograph of the electrode with uniform specific radioactivity taken after 52 cycles. 


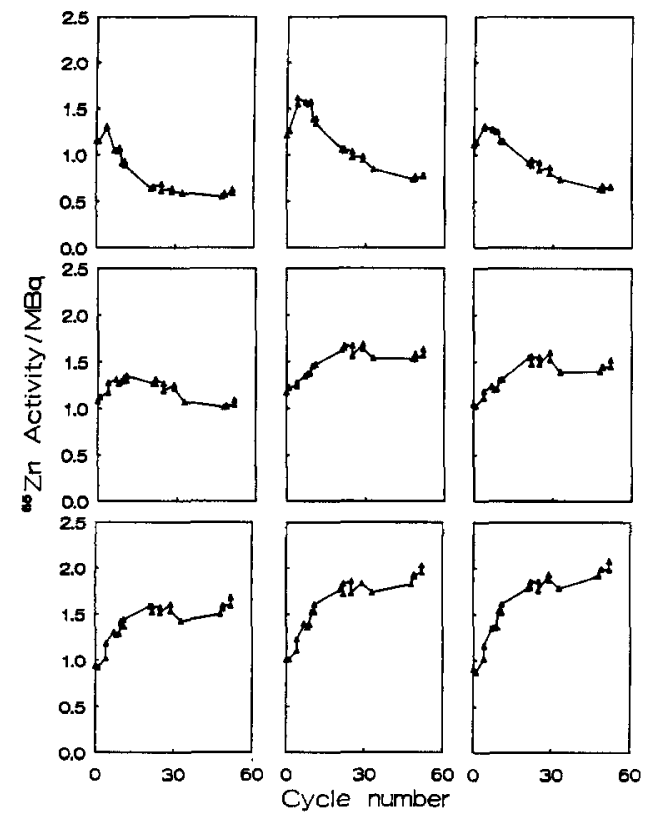

Fig. 9. The change in radioactivity $\left({ }^{65} \mathrm{Zn}\right)$ at the nine regions on the electrode (cf. Fig. 3) during cycling of the battery with initially only rodioactive electrolyte. Measurements are performed with the conical collimator.

trolyte is transported out of and into the electrode pack due to forced convection as the cell is charged and discharged, respectively. So, most likely, zinc material is transported over the electrode by convection rather than by diffusion.

The mercury additive and zinc electrode shape change.When mercuric oxide is added to the zinc battery electrode it is reduced to metallic mercury at the beginning of the first charge half-cycle. This is observed clearly from the cell voltage and zinc electrode potential which are both considerably lower at the beginning of the first charge half-cycle as compared with batteries with additive-free zinc electrodes or with mercuric-oxide containing electrodes during subsequent charge half-cycles.

The capacity curve differs from the curve observed for additive-free batteries, cf. Fig. 4. A steeper decline and al-

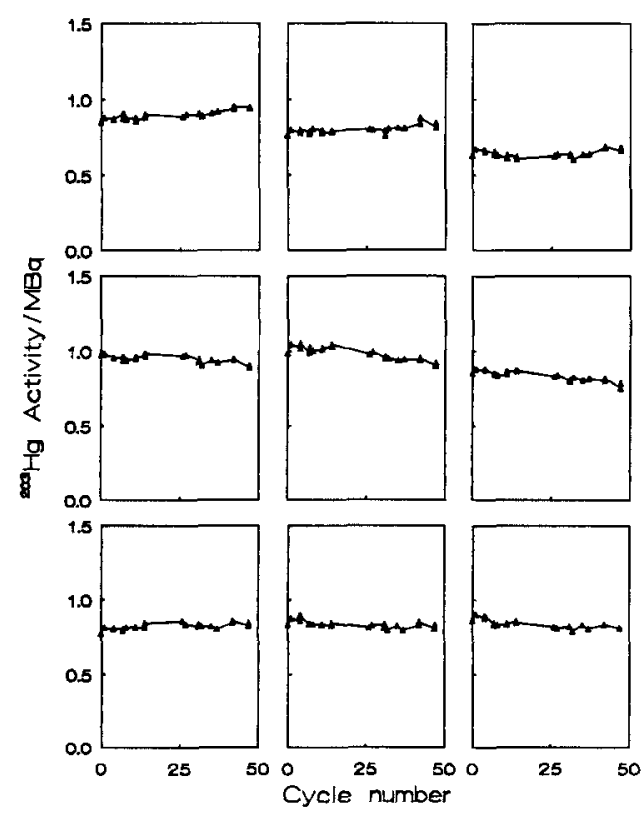

Fig. 10. The change in radioactivity $\left({ }^{203} \mathrm{Hg}\right)$ at the nine regions on the electrode (cf. Fig. 3) during cycling of a battery with a mercurycontaining zinc electrode. Measurements are made with the rectangular collimator. most no plateau value of the relative capacity are observed. Also, a shorter battery cycle life is found for the mercury containing electrodes. After dismantling of the cell, zinc electrode shape change is observed. It was noticed that part of the silver-plated current collector was amalgamated, most noticeably at regions depleted in zinc material.

The experiments with ${ }^{203} \mathrm{Hg}$ are carried out with electrodes with uniform specific radioactivity, i.e., a constant ratio of ${ }^{203} \mathrm{Hg}$ radioactivity to the total mercury material, using the rectangular collimator in the measurements. Figure 10 presents the ${ }^{203} \mathrm{Hg}$ radioactivity distribution over the zinc electrode as a function of cycle number. During cycling the distribution of the radioactivity changes only marginally and thus, the spatial distribution of mercury does not alter significantly. Hence, it can be concluded that the mercury additive is not transported over the electrode. Also, these experiments show that zinc material transport as a result of detachment of electrode mass is highly unlikely; since, if this type of transport occurs, mercury transport must be observed.

The shorter cycle life of batteries with mercury-containing zinc electrodes is attributed to the more rapidly developing shape change process (11-13). McBreen suggested that the mercury-oxide additive, which is reduced to mercury during the first charge period, increases the polarizability of the zinc electrode $(17,18)$, thus causing a more nonuniform current density distribution, and hence, an accelerated shape change behavior (8). However, it was pointed out (19), that the polarizability of the mercurycontaining and additive-free porous zine electrode is similar in magnitude.

Other authors $(11,13)$ observed that during repeated cycling the zinc electrode becomes depleted in additives, due to detachment of zinc material and loss to the electrolyte and separator, which occurs more rapidly than zinc electrode shape change. However, the results given in Fig. 10 do not show that mercury species are displaced over the electrode. As the radiotracer distribution remains virtually constant during repeated cycling, it is unlikely that the mercury additive is transported over the electrode.

Melnicki et al. (20) argued that codeposition of mercury could influence the zinc deposit morphology and hence, zinc electrode shape change. The codeposition of mercury during charge implies that mercury species are present in the battery electrolyte, probably as the mercurate ion. The concentration of the mercurate ion in solution will be very small, since, apart from the high anodic potential needed to oxidize mercury in the zinc electrode, the solubility of the oxidation product, mercuric oxide, in this medium is very low (20). Also, assuming that an electrolyte flow is induced in the zinc electrode compartment $(3,9,10)$, a net transport of the mercury radiotracer over the electrode should be observed, since the mercury radiotracer will be present in solution predominantly during discharge. However, our results (cf. Fig. 10) point out that no net transport of mercury species and probably, no transport of mercury species occurs at all. Hence, the codeposition of mercury is unlikely to be the cause for the accelerated shape change behavior.

An answer to the role of mercury cannot be given solely on the basis of the data obtained from the radiotracer measurements. However, the radiotracer measurements show that during battery cycling the mercury-zinc ratio over the electrode varies considerably, since the zinc material distribution changes (cf. Fig. 5-8) but the spatial distribution of mercury species does not change (cf. Fig. 10). The mercury-zinc ratio decreases at positions where zinc material accumulates and it increases at positions depleting in zinc material. The changing mercury-zinc ratio over the electrode is hardly an explanation for the observed accelerated shape change behavior. It shows that if processes at the zinc electrode are affected by the mercury additive, the differences in mercury-zinc ratio over the electrode enlarges its effect.

\section{Conclusions}

The radiotracer experiments with ${ }^{65} \mathrm{Zn}$ on the electrode show that during repeated charge-discharge cycling the 
redistribution of zinc material over the electrode, and so, shape change of the zinc electrode, can be monitored in situ. The results display that during repeated cycling zine material is displaced gradually from the top towards the bottom of the electrode.

The mercury radiotracer experiments clearly indicate that mercury is not displaced over the zinc electrode during cycling of the battery.

\section{Acknowledgments}

The authors wish to thank Mrs. C. Zegers (IRI, Delft) for the radiochemical analysis of the many electrode samples and the staff of the SBD (TUE, Eindhoven) for technical consultations and for assistance with the radiochemical experiments.

Manuscript submitted June 29, 1989; revised manuscript received May 13,1990 .

Eindhoven University of Technology assisted in meeting the publication costs of this article.

\section{REFERENCES}

1. D. Hamby, J. Kucera, E. Miller, and N. J. Hover, in "Transport Processes in Electrochemical Systems," (PV 82-10) R. S. Yeo, T. Katan, and D.-T. Chin, Editors, p. 244, The Electrochemical Society Softbound Proceedings Series, Pennington, NJ (1982).

2. J. J. Lander and J. E. Cooper, Report AFAPL-TR-7132, Wright-Patterson Air Force Base, $\mathrm{OH}$ (1971).

3. K. W. Choi, D. N. Bennion, and J. Newman, This Journal, 123, $1616(1976)$.

4. D. C. Hamby, N. J. Hoover, J. Wirkkala, and D. Zahnle, ibid., 126, 2110 (1979).
5. J. Hendrikx, Ph.D. Thesis, Eindhoven University of Technology, Eindhoven (1984).

6. R. G. Gunther and R. M. Bendert, This Journal, 134, 782 (1987).

7. S. P. Poa and G. H. Wu, J. Appl. Electrochem., 8, 427 (1978).

8. J. McBreen, This Journal, 119, 1620 (1972).

9. R. E. F. Einerhand, W. Visscher, E. Barendrecht, and J. J. M. de Goeij, in Vol. II, p. 751, Extended Abstracts of the 38th ISE Meeting, Maastricht (1987).

10. E. H. Hietbrink and R. F. Hill, This Journal, 136, 310 (1989).

11. A. Himy and O. Wagner, in "Proceedings of the 28 th Power Sources Conference," Atlantic City, NJ, June $12-15$, 1978, The Electrochemical Society, Inc.,
p. 167.

12. J. McBreen and E. Gannon, Electrochim Acta, 26, 1439 (1981).

13. A. Himy and R. Karcher, Abstract 90, p. 246, The Electrochemical Society Extended Abstracts, Vol. 80-2, Hollywood, FL, Oct. 5-10, 1980.

14. R. E. F. Einerhand, Ph.D. Thesis, pp. 118-127, Eindhoven University of Technology, Eindhoven (1989).

15. R. E. F. Einerhand, W. Visscher, J. J. M. de Goeij, and E. Barendrecht, This Journal, 138, 7 (1991).

16. T. P. Dirkse, L. A. van der Lugt, and N. A. Hampson, This Journal, 118, 1606 (1971).

17. J. McBreen and E. Gannon, ibid., 130, 1980 (1983).

18. J. McBreen and E. Gannon, J. Power Sources, 15, 169 (1985).

19. R. E. F. Einerhand, Ph.D. Thesis, Chap. 4, pp. 48-82, Eindhoven University of Technology, Eindhoven (1989)

20. L. S. Melnicki, I. Lazic, and D. Cipris, Final Report, N00014-82-c-0701, Morristown, NY (1985).

\title{
Zinc Electrode Shape Change
}

\section{Process and Mechanism}

\author{
R. E. F. Einerhand ' and W. Visscher
}

Laboratory for Electrochemistry, Eindhoven University of Technology, $5600 \mathrm{MB}$ Eindhoven, The Netherlands

\author{
J. J. M. de Goeii
}

Laboratory for Instrumental Analysis, Eindhoven University of Technology, $5600 \mathrm{MB}$ Eindhoven, The Netherlands and Interfaculty Reactor Institute, Delft University, $2629 \mathrm{JB}$ Delft, The Netherlands

\section{E. Barendrecht}

Laboratory for Electrochemistry, Eindhoven University of Technology, 5600 MB Eindhoven, The Netherlands

\section{ABSTRACT}

The process and mechanism of zinc electrode shape change is investigated with the radiotracer technique. It is shown that during repeated cycling of the nickel oxide/zinc battery zinc material is transported over the zinc electrode via the battery electrolyte. During charge as well as during discharge zinc material is transported over the electrode. The direction of the zinc material transport during charge is opposite its direction during discharge. The amount of zinc material displaced over the electrode during charge is smaller than during discharge, so that after one charge-discharge cycle the net zinc material transport is observed in the direction as found during discharge. A new model for shape change is presented: the density gradient model. The model is based on the occurrence of an electrolyte flow during repeated charge-discharge cycling of the zinc secondary battery, which transports zinc material over the electrode. During battery cycling this electrolyte flow arises as a result of density gradients in the solution layer adjacent to the zinc electrode and of volume variations of the battery electrolyte.

The principal failure mode of nickel oxide/zinc secondary batteries is the gradual degradation of the zinc electrode, mainly as a result of the redistribution of zinc material over the electrode during repeated charge-discharge cycling, i.e., zinc electrode shape change. Two models for zinc electrode shape change have been developed: the membrane pumping model, due to Choi et al. (1), and the

${ }^{1}$ Present address: Philips Research Laboratories, 5600 JA Eind hoven, The Netherlands. concentration cell model, due to the McBreen (2). Choi et al. (1) state that electro-osmosis and osmosis cause forced convection in the zinc electrode compartment. The properties of the membrane separator, usually a weak cationic membrane, the presence and relative position of an electrolyte reservoir and the electrolyte between the battery plates determine the direction and rate of this convective flow. The changes in zincate concentration and flow direction during the charge and discharge half-cycles result in a net movement of zinc species in the direction 